\title{
Educação e Direitos Humanos: A Experiência Pedagógica na Formação Docente ${ }^{1}$
}

\author{
MAGALHÃES, Solange Martins Oliveira ${ }^{2}$
}

\section{Resumo}

A compreensão, propagação e prática de uma educação em direitos humanos vêm exigindo, sobretudo das universidades públicas, maior discussão e posicionamento a respeito dos temas abordados na formação docente, principalmente, em relação aos temas transversais, como os direitos humanos e sua interdisciplinaridade. A formação de professores e, posteriormente, a educação, se configuram como espaço de uma ação essencial que pode possibilitar o acesso real a todos os direitos. Assim pensando, esse artigo apresenta a temática Direitos Humanos, articulada à prática formadora, nos moldes de oficinas pedagógicas, segundo as exigências do Plano Nacional de Educação em Direitos Humanos (PNEDH-3) e a Declaração Universal de Direitos Humanos. Os resultados mostram a ação docente como práxis, libertadora e emancipadora, além de geradora de criticidade, valorização e respeito aos direitos fundamentais.

\section{Direitos Humanos. Educação em Direitos Humanos. Formação de Professores.}

\section{Resumen}

La comprensión, propagación y práctica de una educación en derechos humanos viene exigiendo, sobre todo de las universidades públicas, mayor discusión y posicionamiento acerca de los temas abordados en la formación docente, principalmente, en relación a los temas transversales, como los derechos humanos y su interdisciplinariedad. La formación de profesores y, posteriormente, la educación, se configuran como espacio de una acción esencial que puede posibilitar el acceso real a todos los derechos. De esa manera, en este artículo se presenta la temática Derechos Humanos, articulada a la práctica formadora, en los moldes de talleres pedagógicos, según las exigencias del Plano Nacional de Educação em Direitos Humanos (PNEDH-3) y la Declaración Universal de Derechos Humanos. Los resultados muestran la acción docente como praxis, liberadora y emancipadora, además de generadora de criticidad, valorización y respeto a los derechos fundamentales.

Derechos Humanos. Educación en Derechos Humanos. Formación de Profesores.

\footnotetext{
${ }_{1}^{1}$ Pesquisa financiada pelo CNPQ - Conselho Nacional de Desenvolvimento Científico e Tecnológico. 2 Doutora e Mestre em Educação pela Universidade Federal de Goiás/Brasil. Professora da Graduação em Pedagogia e do Programa de Pós-Graduação em Educação, da Faculdade de Educação, Universidade Federal de Goiás. É professora convidada da Facultad de Humanidades y Ciencias Sociales, da Universidad Nacional de Jujuy/Argentina.
} 


\section{Introdução}

Quem acredita nos direitos humanos procura transformar a possibilidade teórica em realidade. Antonio Candido

As características específicas da Educação em direitos humanos, tanto em nível temático, como em suas especificidades conceituais e metodológicas, têm sido postas em pauta desde as últimas décadas do século $X X$, quando se volta a fortalecer a ideia que os direitos humanos por serem fundamentais, deveriam permear as discussões sobre a educação. No processo, resgata-se a íntima conexão que existe entre a educação e os direitos humanos, sobretudo por se considerar que a finalidade última da educação é promover o desenvolvimento de sujeitos, para que dominem e defendam conhecimentos relativos aos valores públicos, vinculados à democracia e aos próprios direitos humanos.

Nos documentos da educação, como a Lei de Diretrizes e Bases (LDB, 1996) e as Diretrizes e os Parâmetros Curriculares Nacionais (1998), temos metas da educação, como: emancipar, conscientizar, humanizar, promover valores, autoconhecimento, autonomia, gerar reconhecimento e afirmação dos direitos e dignidade humana. Nessas leis, associadas a um conjunto maior, reforça-se que a meta do educar seja para o exercício da cidadania, da formação ética e solidária. Entretanto, como afirmam Carvalho et al. (2004, p. 437), é "necessário reconhecer que a aceitação dessa meta como principal diretriz educacional tem sido mais retórica do que prática", pois isso envolveria uma série de medidas complementares, dentre as quais, uma que mais nos interessa relaciona-se a formação de professores.

Concordamos com Carvalho et al. (2004, p. 437), quando afirmam que existe uma ênfase discursiva em relação à proclamação dos ideais da cidadania e da igualdade, mas, na verdade, o que se percebe é o como o caráter ideológico neoliberal permeia a educação, exigindo que responda muito mais ao mercado de trabalho, do que para seu potencial social e público.

O mesmo acontece no campo da formação docente, as atuais políticas educacionais desmontam uma proposta voltada a promoção do bem comum, uma vez que têm reforçado uma formação aligeirada, geralmente à distância, voltada ao desenvolvimento de habilidades e competências, em respostas às exigências de organismos internacionais. Estrutura-se um movimento que transforma as diretrizes de uma educação em direitos humanos, em um repertório temático, com algumas metodologias, ditas inovadoras, que simplificam a questão da educação para a democracia e os direitos humanos. Em outros casos, Ihe é dada a conotação de modismo, que consegue temporariamente promover a transmissão de informações, por alguns professores, sempre de forma isolada, o que é um equívoco. 
Pensar que apenas apresentar o conteúdo da Declaração dos Direitos Humanos, ou o como os princípios da Constituição da República (1988), reforçam que os direitos humanos se referem a democracia, a paz e o desenvolvimento socioeconômico, como essenciais para garantir a dignidade da pessoa humana, por exemplo, atendendo apenas as deliberações dos Parâmetros Curriculares Nacionais, será suficiente para gerar conceitos e práticas vinculados à educação para cidadania.

Afinal, não será uma tematização esporádica que garantirá a adesão dos sujeitos, tampouco a promoção de um mundo melhor, sobretudo, porque como parte desse mundo está a escola, onde se pode presenciar toda sorte de discriminação, exclusão, violências, e ações relacionadas a violações concretas de direitos. Em se tratando de educação, de modo geral, a proclamação de direitos e sua efetivação, ainda está bastante distante, pois como bem sabemos, a escola é portadora de uma série de problemas complexos e, tanto os professores como os alunos, convivem com cada um deles, sendo que alguns desqualificam e desmobilizam o próprio trabalho docente.

Como afirmam Carvalho et al. (2004, p. 437), citando Sesti et al. (2004),

o sentido de uma educação comprometida com os ideais e valores da cidadania, da democracia e dos direitos humanos se expressa menos nas informações e nos discursos transmitidos do que nos princípios de condutas que regem, no cotidiano escolar, as ações educativas de uma instituição.

Como se afirma na epígrafe: quem acredita nos direitos humanos procura transformar a possibilidade teórica em realidade, e esse é um problema que está diretamente relacionado à universidade pública, aos órgãos governamentais e a escola, que num esforço coletivo e conjunto, precisam empreender ações, que respondam a função pública da educação. Justifica-se promover uma discussão que resgate os parâmetros da ação ética e os compromissos da educação com a emancipação.

Portanto, a compreensão, propagação e prática de uma educação em direitos humanos vêm exigindo, sobretudo das universidades públicas, maior discussão e posicionamento a respeito dos temas abordados na formação, principalmente, em relação aos temas transversais, como estão postos os direitos humanos e sua interdisciplinaridade. Entendemos que a formação de professores e, posteriormente, a educação, se configura como espaço de uma ação essencial que pode possibilitar a compreensão, exigência e o acesso real aos direitos fundamentais. 


\section{Educação em Direitos Humanos (EDH)3}

A Educação em Direitos Humanos mostra-se essencial para a formação de uma cultura de respeito à dignidade humana e acesso a cidadania. Entende-se que ela deve estruturar-se na diversidade cultural e ambiental, garantindo 0 acesso à educação de qualidade social, permanência e conclusão, e a equidade (étnico-racial, religiosa, cultural, territorial, físicoindividual, geracional, de gênero, de orientação sexual, de opção política, de nacionalidade, dentre outras).

Esse formato de educação baseia-se na Declaração Universal dos Direitos Humanos (DUDH) ${ }^{4}$, formulada pela Assembleia Geral das Nações Unidas, em 10 de dezembro de 1948, em São Francisco, Califórnia, nos Estados Unidos, que se pretendia ter validade universal, como postulação que atingisse quaisquer grupos e países, em todas as situações. Entretanto, se tomarmos os trinta itens da Declaração Universal dos Direitos Humanos, e os checarmos com o que sabemos acerca das relações internacionais, tais como se apresentam no quotidiano mundial, o mesmo no caso da contemporaneidade civil e política brasileira, eles se apresentam como uma postulação bastante esvaziada enquanto regime universal, mas, por sua importância, isso não pode nos impedir de pensar suas afirmações (MAGALHÃES, 2011).

Como afirmou Lindgren Alves (1996), os aspectos positivos de sua promulgação cumprem um papel extraordinário na história da humanidade. Codificou as esperanças dos oprimidos, fornecendo uma linguagem autorizada à semântica de suas reivindicações. Também proporcionou base legislativa às lutas políticas pela liberdade e inspirou a maioria das Constituições Nacionais, que se preocuparam com a positivação dos direitos da cidadania.

No sentido jurídico, a Declaração Universal dos Direitos Humanos modificou o sistema das relações internacionais, que tinha como atores exclusivos os Estados soberanos, conferindo às pessoas a qualidade de sujeito do Direito. No sentido sócio-político, mobilizou consciências e agências, governamentais e não-governamentais, para atuações solidárias, estabelecendo legalidade a aferição da legitimidade de qualquer governo, substituindo a eficácia da força pela força da ética.

Esboçando uma sociedade civil transcultural como possível embrião de uma verdadeira comunidade internacional, conforme afirmou Magalhães (2011), os direitos humanos representam os direitos fundamentais, "equivalem às necessidades humanas fundamentais" (DALLARI, 2004, p. 25), como, por

\footnotetext{
${ }^{3}$ Programa Nacional de Direitos Humanos, disponível na Internet em: <http://www.mi.gov.br/sedh/ct/spddh/pnedh.pdf>. Acesso em 07/08/2017.

${ }^{4}$ Declaração Universal dos Direitos Humanos, disponível em: $<$ http://www.educacao.mppr.mp.br/arquivos/File/dwnld/educacao basica/educacao\%20infantil/legislacao/d eclaracao universal de direitos humanos.pdf> . Acesso em 06/08/2017.
} 
exemplo, os direitos à vida, à saúde, à educação, à dignidade, são fundamentais para que os sujeitos tenham condições mínimas para viver, conviver e se desenvolver. Por isso tornam-se universais, reconhecê-los, protegê-los e promovê-los está relacionado a preservação da dignidade humana, que deve ser garantida a todos, da mesma maneira, a despeito da etnia, gênero, religião, ou classe social.

Os direitos humanos, em seu processo de construção, foram divididos em: direitos civis, direitos políticos, e os direitos coletivos da humanidade, formulados em três gerações, as quais, no sentido histórico, configuram um caráter de complementaridade: a primeira geração é contemporânea das revoluções burguesas do final do século 18 e de todo o século 19. Representa os direitos civis e das liberdades individuais, liberdades consagradas pelo liberalismo, quando o direito do cidadão se dirige contra a opressão do Estado ou de poderes arbitrários; contra as perseguições políticas e religiosas, pregando a liberdade de viver sem medo. Os direitos da primeira geração dizem respeito ao direito à vida, à segurança, à intimidade, à propriedade, à manifestação, à opção religiosa e a liberdades civis, o que implica na obrigação do Estado, no respeito à pessoa humana e na garantia de seus direitos. A segunda geração, não abrange apenas os indivíduos, mas os grupos sociais. Surge no início do século 20, na esteira das lutas operárias e do pensamento socialista na Europa Ocidental. A segunda geração de direitos explicitou na prática a experiências da social democracia, para consolidar-se, ao longo do século, nas formas do Estado do Bem-Estar Social. Refere-se ao conjunto dos direitos sociais, econômicos e culturais, como os de caráter trabalhista e os de caráter social mais geral, como saúde, educação, habitação, acesso aos bens culturais.

Em complemento às duas gerações, surge a terceira geração que traz os direitos coletivos da humanidade, como: direito à paz, ao desenvolvimento, à autodeterminação dos povos, ao patrimônio científico, tecnológico e cultural da humanidade, ao meio ambiente ecologicamente preservado. São os direitos ditos de solidariedade (BENEVIDES, 2000; CARVALHO, 2004, 2010, MAGALHÃES, 2011).

Apesar da Declaração Universal dos Direitos Humanos ser quase septuagenária, a realidade mostra que os direitos nela propostos, ainda não são, consistentemente, respeitados em nenhuma comunidade, nacional ou eletiva, real ou imaginária. Mas devemos compreender que o Direito é um discurso normativo que aspira a conformação da realidade. Nesse sentido, dada sua força persuasiva e seu ideal liberatório, a Declaração de 1948 precisa ser mantida como está, e devemos insistir para que todos os povos consigam compreender e vivê-la, como opção democrática de vida. Acreditamos que nesse percurso a Educação em Direitos Humanos torna-se fundamental. Só assim poderemos tentar consolidar seus objetivos. 
Somente 50 anos depois de seu nascimento, portanto, na década de 1990, que a Organização das Nações Unidas (ONU) declarou que o período de $1^{\circ}$ de janeiro de 1995 a 31 de dezembro de 2004, se constituiria como a Década das Nações Unidas para a Educação em Direitos Humanos. No documento apresentado, ela era assim conceituada esse tipo de educação:

[...] objetiva a construção de uma cultura universal de direitos humanos através da partilha de conhecimento [...] direcionados ao fortalecimento do respeito aos direitos humanos e liberdades fundamentais; ao desenvolvimento completo da personalidade humana e de seu senso de dignidade; à promoção da compreensão, tolerância, igualdade entre os sexos e amizade entre todas as nações, pessoas e grupos raciais, nacionais, étnicos, religiosos e linguísticos; à capacitação de todas as pessoas a participar efetivamente de uma sociedade livre; à ampliação de atividades das Nações Unidas para a manutenção da paz. (MAIA, 2007, p. 85).

Durante a Década das Nações Unidas para a Educação em Direitos Humanos, ocorreram diferentes esforços, treinamentos e disseminação de informações sobre uma cultura universal de direitos humanos, o que ocorreu por meio da transmissão de conhecimentos e competências, com vista a:

(a) reforçar o respeito pelos direitos humanos e liberdades fundamentais; (b) desenvolver em pleno a personalidade humana e o sentido da sua dignidade; (c) promover a compreensão, a tolerância, a igualdade entre os sexos e a amizade entre todas as nações, povos indígenas e grupos raciais, nacionais, étnicos, religiosos e linguísticos; (d) possibilitar a participação efetiva de todas as pessoas numa sociedade livre; (e) promover as atividades das Nações Unidas em prol da manutenção da paz. (PIOVESAN; FACHIN, 2017, p. 27).

Além do estabelecimento dessas competências, conforme Piovesan e Fachin, a Organização das Nações Unidas enumerou cinco objetivos que deveriam ser alcançados na Década das Nações Unidas, em Matéria de Direitos Humanos:

(i) avaliação de necessidades e a formulação de estratégias eficazes para a promoção da educação em matéria de direitos humanos a todos os níveis do sistema escolar, na formação profissional e formal, bem como na aprendizagem não formal;

(ii) A criação e o reforço de programas e capacidades para a educação em matéria de direitos humanos a nível internacional, regional, nacional e local;

(iii) $O$ desenvolvimento coordenado de materiais didáticos para a educação em matéria de direitos humanos; 
(iv) O reforço do papel e da capacidade dos meios de comunicação social no fomento da educação em matéria de direitos humanos;

(v) A divulgação da Declaração Universal dos Direitos do Homem a nível mundial, no máximo número de línguas possível e de outras formas apropriadas para os vários níveis de alfabetização e para os deficientes. (PIOVESAN; FACHIN, 2017, pp. 28-29).

O Programa decorrente da década de ação encerrou-se em 2004, mas como descrevem Piovesan e Fachin (2017, p. 28-29), a fim de dar sequência ao que se vinha construindo na Década das Nações Unidas, em Matéria de Direitos Humanos, em dezembro de 2004, a Assembleia Geral da ONU lançou - Programa Mundial para Educação em Direitos Humanos, reeditando as diretrizes anteriormente estabelecidas. O programa foi dividido em três etapas: a primeira abrangeu o período entre 2005 e 2007, e formulou recomendações e metas para o ensino fundamental e médio.

Nessa primeira fase, o enfoque se desmembrou em duas diretivas:

(i) os Direitos Humanos no contexto educativo, isto é, envolver a integralidade do processo de aprendizagem - desde a elaboração de materiais didáticos até a adoção de métodos pedagógicos - dentro da estratégia de promoção da educação em Direitos Humanos; e (ii) a realização dos Direitos Humanos na educação, posto que o respeito aos Direitos Humanos deve predominar entre os membros da comunidade escolar colocando em prática o seu exercício. (PIOVESAN; FACHIN, 2017, p. 29).

A segunda etapa, que teve duração de quatro anos, tendo como ponto de partida o ano de 2010, quando houve investimento no ensino superior e à formação em Direitos Humanos para professores, servidores públicos, membros das forças de segurança e agentes policiais e militares. O Ministério da Educação foi designado como ator responsável pela implementação do Plano de Ação, em colaboração com as instituições de ensino superior (PIOVESAN, FACHIN, 2017).

A terceira etapa, cuja conclusão se dará no ano de 2019, é direcionada à formação em Direitos Humanos dos profissionais da mídia e dos jornalistas (PIOVESAN, FACHIN, 2017).

No desenvolvimento das etapas citadas, o Programa Mundial para Educação em Direitos Humanos, no ano de 2008, por ocasião da comemoração aos 60 anos da Declaração Universal, a ONU decretou o ano como "Ano Internacional de Educação em Direitos Humanos", tomando diversas medidas para fortalecer a implantação da Educação em Direitos Humanos.

Em 2011, foi aprovada a Resolução no 66/137/ONU que deu origem à Declaração das Nações Unidas sobre a Educação e Formação em Direitos Humanos, que no seu artigo primeiro artigo, consolida o seguinte reconhecimento: 
Artigo 1.1 Todas as pessoas têm direito, a saber, a procurar e receber informações sobre todos os direitos humanos e liberdades fundamentais e devem ter acesso à educação e à formação em matéria de direitos humanos. (ONU, 2011).

A Declaração fortaleceu a relação direta entre os direitos humanos e o processo educativo, influenciando decisões e mudanças educacionais nos países signatários. No Brasil, houve abertura exponencial as diretrizes da ONU, uma vez que o desenho constitucional do país, favorecia sua conexão com o plano internacional. Quer seja a Constituição Federal (1988), como a Lei de Diretrizes e Bases da Educação (1996), Parâmetros Curriculares da Educação, o Programa Nacional de Direitos Humanos e o Plano Nacional de Educação em Direitos Humanos, respondiam as diretrizes e ações direcionadas à formação cidadã.

A Constituição Federal (1988), por exemplo, reflete o mesmo ideal, sobretudo ao dispor sobre os princípios e fins da educação nacional. No art. $2^{\circ}$ da nossa Constituição (1988), temos que a educação, dever da família e do Estado, deve ser inspirada nos princípios de liberdade e nos ideais de solidariedade humana, tem por finalidade o pleno desenvolvimento do educando, seu preparo para o exercício da cidadania e sua qualificação para o trabalho. Por este ângulo, a Resolução no 66/137/ONU é legitimada, uma vez que, como descrevem Fernandes e Candau (2017, p. 3), "o direito à educação é um direito prioritário, mas não é direito a uma educação qualquer: é direito a uma educação com qualidade de direito do homem".

Reforça-se o que está posto na Declaração Universal dos Direitos Humanos (1948), para a qual a educação é um direito humano universal, posta no mesmo patamar do direito à vida, à segurança, à paz, à saúde e ao bemestar, estabelecendo a real e concreta relação entre o direito humano à educação e o educar em direitos humanos:

Art. 26.

1. Toda pessoa tem direito à educação. A educação deve ser gratuita, pelo menos a correspondente ao ensino elementar fundamental. $O$ ensino elementar é obrigatório. $O$ ensino técnico e profissional deve ser generalizado; o acesso aos estudos superiores deve estar aberto a todos em plena igualdade, em função do seu mérito.

2. A educação deve visar à plena expansão da personalidade humana e ao reforço dos direitos do Homem e das liberdades fundamentais e deve favorecer a compreensão, a tolerância e a amizade entre todas as nações e todos os grupos raciais ou religiosos, bem como o desenvolvimento das atividades das Nações Unidas para a manutenção da paz (Declaração Universal dos Direitos Humanos. ONU, 1948).

Sendo assim, os direitos humanos são concebidos como princípio e conteúdo do direito à educação, mas para que isso ocorra, como afirmam Fernandes e Candau (2017, p. 4), é necessário que a educação em direitos humanos para que se "propicie expandir a humanidade de cada pessoa e ainda reforce o reconhecimento dos direitos e do seu exercício". 
Isso implica, particularmente, numa formação docente voltada às práticas de cidadania que consolide o sentido de educar numa perspectiva democrática, o que envolve reconhecer a educação como direito social, "condição necessária, ainda que não suficiente, para o exercício de todos os direitos, sejam eles civis, políticos, sociais, econômicos ou de qualquer outra natureza". (SAVIANI, 2013, p. 745). Para o autor, esse educar pode ajudar a compreender as estreitas relações entre a educação, cidadania, e direitos humanos, pois para que o cidadão se torne ativo e participativo na sociedade, há a necessidade da compreensão e efetivação de todos os seus direitos civis, políticos e sociais.

A partir da enunciação de educação como direito humano e social, tomase o Plano Nacional de Educação em Direitos Humanos (PNEDH-3), proposto pela Secretaria Especial dos Direitos Humanos (SEDH), lançado pelo Governo Federal, através do Ministério de Educação e da Secretaria Especial dos Direitos Humanos (SEDH), em 10 de dezembro de 2003, o instrumento que iria orientar e nortear as ações educativas de forma pluridimensional, quer seja pública e/ou privada; formal e não formal:

O PNEDH entende os direitos humanos no seu sentido amplo,
decorrentes da dignidade do ser humano, abrangendo, entre
outros: o direito à vida com qualidade, à saúde, à educação, à
moradia, ao lazer, ao meio ambiente saudável, ao saneamento
básico, à segurança, ao trabalho e à diversidade cultural.
Educar em direitos humanos é fomentar processos de
educação formal e não formal, de modo a contribuir para a
construção da cidadania, para o conhecimento dos direitos
fundamentais, o respeito à pluralidade e à diversidade sexual,
étnica, racial, cultural, de gênero e de crenças religiosas.
(BOCK; GIANFALDONI, 2010, p. 98-99).

A fim de cumprir com o comando constitucional e também com as diretrizes oriundas dos planos nacionais de direitos humanos, que indicam que na diretriz 18 do PNDH-3 exige-se a efetivação das diretrizes e dos princípios da política nacional de educação em direitos humanos, para fortalecer a cultura de direitos (BRASIL, 2007), em 2003 foi instituída a política pública da educação em direitos humanos, revista em 2006, por meio da ação conjunta de instituições governamentais, sociais e internacionais, para difundir a cultura de direitos humanos no país, desdobrando-se as seguintes vertentes: Educação formal (básica e superior), Educação não-formal, Educação e Mídia e Educação e Segurança.

À luz do nosso contexto interno e internacional, a perspectiva do PNEDH-3 a educação é a base constitutiva da defesa e constituição dos direitos econômicos, sociais e culturais. E, conforme Candau (2000; 2012), a educação em direitos humanos pode dar conta da valorização e 
reconhecimento das diferenças, de uma formação humanizadora, para que se consolidem os valores para uma cidadania participativa.

A proposta acolhe um novo modelo de formação e, posteriormente, de escola, que valoriza a criatividade, o sonho, o lúdico, o prazer, a alegria, a sensibilidade, a capacidade humana de indignar-se, de ser crítico, de duvidar. Trata-se de favorecer um modelo formativo, sobretudo aos professores, que gere a compreensão de uma educação dialógica, problematizadora, capaz de estabelecer o diálogo, reconhecer o outro, e que promova o desenvolvimento de uma práxis pedagógica.

Entretanto, sempre é válido considerar que o consequente caráter libertário da educação em direitos humanos, não depende apenas do processo formativo, depende das políticas e da garantia dos próprios direitos em si, sua efetivação, para entendermos que a educação faz parte de um processo que busca universalizar seu conhecimento. Assim, a expansão dos direitos humanos, quer seja para os alunos ou para os professores, é ao mesmo tempo, fim e meio para o processo educacional sobre eles pautado.

À guisa de conclusão, seguindo os passos de Candau (2007), destacamos três elementos fundamentais para a formação em direitos humanos:

(i) O primeiro elemento diz respeito justamente à formação de sujeitos de direito em nível pessoal e coletivo. (ii) $\mathrm{O}$ segundo deles é o empoderamento, isto é, as pessoas que não possuem poder nas decisões e nos processos coletivos dentro da sociedade por serem minoradas devem tomá-lo para si. (iii) O terceiro abarca os processos de transformação para construção de uma sociedade democrática e humana. (CANDAU, 2007, pp. 404-405).

Esses elementos sustentam uma formação docente para a mudança, e não para a conservação das velhas estruturas injustas. Portanto, comprometida com os princípios da Declaração Universal de Direitos Humanos, cuja metodologia se constitua, como processo sistemático e multidimensional, orientado a formação de sujeitos de direitos. $E$, muito embora, isso não seja exclusividade da ação docente em sala de aula, mas de uma sociedade que se coloca como democrática, a formação contribui com a consolidação de uma concepção de educação libertadora, a partir da qual os professores são passam a ser mediadores de transformações dos sujeitos, da escola e da sociedade.

2 Educação para Direitos Humanos e a formação docente: A Experiência Pedagógica na Universidade 
A tradução dos Direitos Humanos em conquistas concretas e efetivas, de grande alcance social, é um desafio de toda a sociedade que, certamente, passa também pela educação formal e não-formal, em todos os seus níveis.

Padilha

A metodologia da educação em direitos humanos envolve três pontos essenciais: primeiro, educação permanente, continuada e global; segundo, ser voltada para a mudança cultural; terceiro, ser pautada em valores, para superar a mera transmissão de conhecimentos (BENEVIDES, 2007). Na estruturação dessa metodologia utiliza-se de oficinas de direitos humanos (CANDAU, 1995), as quais buscam a humanização, com o foco central de trabalhar a atitude crítica e ética, mas também a sensibilidade, e o respeito ao ser humano.

Como afirmou Freire, o processo pedagógico precisa promover a construção de relações justas, democráticas e do respeito ao pluralismo cultural. Nesse sentido, é certo afirmarmos que as oficinas em direitos humanos consolidam uma metodologia que reafirma a ação pedagógica como exercício contínuo do diálogo, entre educadores e educandos, em busca de emancipação, portanto é práxis.

Assim compreendendo, ao longo de cinco anos de atividade docente, temos trabalhado, sistematicamente, com a metodologia das oficinas de direitos humanos, no campo da formação de professores, cujos resultados têm composto uma ampla pesquisa sobre os referenciais teóricos e o conteúdo programático do PNEDH, implantação e desenvolvimento entre professores (MAGALHÃES, 2011). Nesse percurso, temos avaliado, com os próprios professores, o como percebem sua aprendizagem sobre a temática dos direitos humanos e o como isso influi na sua ação docente.

No planejamento das oficinas, tomou-se como referência a ementa oficial da disciplina "Sociedade, Cultura e Infância", a partir da qual foram propostas as estratégias, que também se valeram de discussões com os alunos sobre o percurso a ser seguido. A disciplina citada, aborda temas relacionados à sociedade, a educação, sua historicidade, e contempla a introdução de temas afins, como cidadania, direitos humanos, o PNEDH-3, que são associados ao conteúdo da disciplina, formatando uma experiência que tem se mostrado frutífera e relevante para a formação do docente.

No que se refere ao procedimento metodológico, o primeiro passo foi a leitura do material teórico proposto - Declaração de Direitos humanos e PNEDH-3, após a leitura, pediu-se ao grupo a realização de discussões ampliadas, que no caso de direitos humanos versaram sobre: efetivação dos mesmos no país, sua relação com preconceitos, racismo, gênero, violência e educação, permitindo perspectivas interativas entre os campos disciplinares, além de revisão e suprimento de eventuais temas que surgissem no momento 
da discussão. Desta forma, oportunizou-se aos alunos, o conhecimento sobre direitos humanos, articulando-os à formação docente e às áreas afins.

O processo exigiu diálogo, dinâmica aberta, fundada na solidariedade, no questionamento constante, para que fosse possível estabelecer reflexões sobre os direitos, relacionadas as ações desenvolvidas pelos estudantes no/com/fora do grupo. A proposta de trabalho levou em consideração a pluralidade dos sujeitos, sua inserção crítica no universo da cultura, do pensamento, da autonomia, da liberdade, da justiça, da democracia e da solidariedade.

O segundo passo foi a leitura e análise de um texto indutor de reflexão, retirado do livro Educar para a conexão (SILVA, 2004). Foram dadas as seguintes orientações: leitura, análise e discussão em grupos do texto "Carta 23", encontrada nos muros de um campo de concentração na Alemanha, após a Segunda Guerra Mundial. Vejamos o texto:

Prezado Professor: Sou sobrevivente de um campo de concentração. Meus olhos viram o que nenhum homem deveria ver. Câmaras de gás construídas por engenheiros formados, crianças envenenadas por médicos diplomados, recémnascidos mortos por enfermeiras treinadas, mulheres e bebês fuzilados e queimados por graduados de colégios e Universidades. Assim, tenho minhas suspeitas sobre a Educação. Meu pedido é: ajude seus alunos a tornarem- se humanos. Seus esforços nunca deverão produzir monstros treinados ou psicopatas hábeis. (SILVA, 2004, p. 87).

Para Silva (2004), essa mensagem foi escrita por alguém que sofreu com a falta de conexão entre os seres humanos. Com essa observação iniciouse o debate acerca do conteúdo da carta, suscitando a reflexão sobre a vivência do valor da igualdade, dignidade e direitos para todos. Debateu-se primeiro o assunto no grande grupo, depois o assunto foi debatido novamente em grupos menores. As conclusões a que os pequenos grupos chegaram, foram apresentadas em formas de oficinas pedagógicas de direitos humanos, como proposto por Candau (1995), sendo que cada uma das oficinas, além de apresentar a conclusão da reflexão do grupo, deveria associa-la a um dos artigos da Declaração Universal de Direitos Humanos - DUDH5.

As oficinas giraram em torno das expressões: teatral, musical, cordel, dança e poesia, cada grupo de estudantes esforçou-se para sua realização, tornando o trabalho criativo e prazeroso. Possibilitou trabalhar as dimensões estética, corporal, sensível, como uma forma de despertar a sensibilidade e a afetividade entre os estudantes. Entendemos que a metodologia utilizada

\footnotetext{
${ }^{5}$ A Declaração Universal de Direitos Humanos pode ser encontrada na Internet em: http://www.mj.gov.br/sedh/ct/legis intern/ddh bib inter universal.htm
} 
maximizou a aprendizagem sobre a temática, o que deveria ser retomado na discussão e análise posterior pelo grupo todo, em plenária geral.

Conforme relatos aqui apresentados, eles foram capazes de trabalhar produtivamente em grupo, refletindo criticamente sobre o material proposto, sobre a sua própria prática e suas ações. Não vamos relatar todo o processo de elaboração e apresentação das oficinas, traremos o resultado obtido e relatado na plenária geral, realizada ao final de todas as apresentações. Estes foram os relatos dos estudantes sobre o seu processo ensino-aprendizagem:

[...] as oficinas pedagógicas explicitaram o como é inconcebível que discriminações e violências sejam tão comuns em nossa (ou outra) sociedade [...] precisamos militar em prol dos direitos humanos sempre, para resgatar a dignidade de todos. Talvez a Educação em Direitos Humanos ajude em curto prazo [...] (sujeito 41).

[...] a oficina teatro me ajudou a vivenciar a dor daquelas pessoas e como isso é duro. Senti angústia diante da expressão de tanta dor [...]. Talvez as minhas palavras não deem conta de expressar a tristeza e a indignação que vivi durante a oficina de teatro (sujeito 7 ).

A aprendizagem significativa acontece quando os estudantes reconstroem o conhecimento com qualidade social, segundo Demo (1999), leva à emancipação e à conquista de sua autonomia pessoal e profissional. A atividade em si, leitura, análise e discussão do conteúdo, mais a elaboração das oficinas, parece ter promovido a capacidade de perceber as consequências pessoais e sociais de nossas escolhas, além da imperiosa necessidade de se desenvolver o senso de responsabilidade social e coletiva.

[...] e escolha da música utilizada na oficina de canto - "Vida de gado" do Zé Ramalho, me marcou muito. Vivenciei o como estamos marcados e o quanto estamos ideologicamente estagnados em função do sistema (sujeito 3).

A complexidade e a abrangência da ação docente, potencialmente transformadora, implica colaborar para que novas reflexões sejam propostas e os estudantes possam acionar sua capacidade auto questionadora e reflexiva.

[...] vivenciar as oficinas pedagógicas me colocou na situação de reflexão e análise, aprendi que devemos ser militantes em prol dos Direitos Humanos, que devemos vivenciar experiências de reconciliação, cooperativas e solidárias. Experiências pautadas no princípio ético, acima dos interesses pessoais, próximas do bem comum e da manutenção da vida [...] (sujeito 17).

[...] a oficina de cordel assumiu o tema educação, e nada mais propício que trazer Paulo Freire para sua construção, porque para ele, além de relacionar o educar com a emancipação e cidadania, afirma que implica em um ato de amor, presente em 
cada palavra, em cada gesto, em cada realização. A EDH pode nos ajudar a ter essa expressão em nossa ação pedagógica [...] (sujeito 10).

Com base nos relatos, promoveu-se os objetivos da EDH, qual seja, a formação de sujeitos capazes de julgar, escolher, tomar decisões, cidadãos responsáveis e prontos para exigir que não apenas seus direitos, mas também que os direitos dos outros, sejam respeitados e cumpridos.

[...] nunca me imaginei trabalhando o corpo. Nunca trabalhei o corpo dos meus alunos. Achei fantástica a oficina de dança. Aprendi que quem educa, educa o corpo do outro (sujeito 9).

[...] adorei, mas ver os colegas se esforçando na elaboração das oficinas, foi o melhor, aprendi muito e desenvolvi o desejo de superar minhas dificuldades, assim como promover esse entendimento em meus alunos. Gostaria de torná-los sensíveis a vida [...] (sujeito 40).

[...] com a oficina pedagógica de dança fui tocada no meu ponto fraco, adoro dançar, participar da oficina de dança foi ótimo. Minha oficina associou dança, beleza e leveza com a solidariedade. Aprendi que poderíamos através do corpo ressignificar as coisas fazendo com que a vida tenha mais sentido, prazer e dignidade [...] (sujeito 2).

É importante destacar que existiram movimentos de resistências entre os estudantes, mas esses foram trabalhados por meio do diálogo e negociações. As resistências enfrentadas durante o processo, serviram para ressignificar o aprender a conviver e respeitar a opinião do outro. E nesse sentido, no processo houve a construção de um pensar mobilizador, que toma a realidade como contraditória e dialética.

A atividade pedagógica também modificou a tradição da sala de aula que é constantemente baseada no baixo nível de participação dos alunos. Ao mudar a ênfase nas atividades tradicionais e solitárias, promoveu-se as bases da comunicação livre e plural, chegando a autonomia e a auto-organização da maioria dos estudantes.

\section{Algumas considerações}

Só se educa em direitos humanos quem se humaniza e só é possível investir completamente na humanização a partir de

uma conduta humanizada.

Ballestrer

Em que pesem os aplausos ou o ceticismo em relação à proposta de uma educação em direitos humanos, sobretudo no âmbito da formação de professores, temos muito a considerar. A metodologia relatada tem-se mostrado bastante significativa, formativa e transformadora, ao longo dos anos do desenvolvimento da pesquisa. Essa prática pedagógica da Educação em 
Direitos Humanos é pautada na práxis, para que fosse possível ser transversal dos conteúdos de direitos humanos.

A práxis destaca que a vivência desses direitos e a coerência com sua promoção, transforma a prática pedagógica, que pode possibilitar uma nova percepção da realidade, histórica e social, podendo gerar atitude emancipadora e transformadora.

A formação dos professores em direitos humanos deve privilegiar as metodologias ativas e participativas, como a apresentada, de forma a envolver e despertar o interesse, sem esquecer o sensibilizar, indignar-se, atuar de forma comprometida, para que o professor em direitos humanos se articule com a historicidade na qual está inserido.

Em síntese, a metodologia para o desenvolvimento da Educação em Direitos Humanos, no ensino superior, requer a seleção e organização dos conteúdos e atividades, materiais e recursos didáticos, que sejam condizentes com a finalidade de um processo educativo em direitos humanos.

Por outro lado, a experiência apresentada também destaca a exigência de uma postura de reflexão e reavaliação das oficinas pedagógicas, pois dependendo da turma, a preocupação exige superar o metodológico, e realmente firmar-se na sustentação dos princípios de ideais dos direitos humanos, da democracia e da cidadania. $O$ foco central é fazer entender aos futuros professores, que a proposta deve ser inspiradora de novas práxis, e não de ações vazias de sentido e significado para eles e seus futuros alunos.

Como professora envolvida no processo, a prática foi revigorante, ampliou o respeito à autonomia do trabalho docente, gerou abertura para o trabalho conjunto, o que foram aspectos vividos como muito positivos e, por isso mesmo, necessitam ser amplamente incentivados nos contextos formativos.

A despeito dos aplausos e ceticismos, fica cada vez mais patente a necessidade de que a formação de professores integre, de forma crescente, os aportes dos direitos humanos e do PNEDH, bem como integre discussões concretas e complexas sobre o seu ponto de vista conceitual, e sobre o como assumem as concepções de educação em articulação com outras concepções como: a violência escolar, racismo, discriminação. Com certeza, essa prática irá repercutir, positivamente, na construção de uma nova ética, entre professores, bem como, uma nova consciência política e social, o que é atualmente bastante desejável.

\section{Referências}

BALLESTRERI, R. Cidadania e Direitos Humanos: um sentido para a educação. Rio Grande do Sul: Pater, 1999.

BENEVIDES, M. V. Educação em Direitos Humanos: de que se trata? Palestra de abertura do Seminário de Educação em Direitos Humanos, São Paulo, 2000. 
BOCK, A. M. M. B.; GIANFALDONI, M. H. T. A. Direitos humanos no ensino de Psicologia. Psicol. Ensino \& Form. [online]. 2010, vol.1, n.2, pp. 97-115. ISSN 21772061.

BRASIL. Lei de Diretrizes e Bases da Educação. Brasília: Ministério da Educação, 1996.

BRASIL. Parâmetros Curriculares Nacionais: introdução aos Parâmetros Curriculares Nacionais. Brasília: Ministério da Educação, 1997.

BRASIL. Parâmetros Curriculares Nacionais: pluralidade cultural. Brasília: Ministério da Educação, 1998.

BRASIL. Programa Nacional de Direitos Humanos (PNDH-3). Brasília: Secretaria Especial dos Direitos Humanos da Presidência da República, 2010.

CANDAU, V. M. et al. Oficinas Pedagógicas de Direitos Humanos. Petrópolis, RJ: Vozes, 1995.

. Educação em Direitos Humanos no Brasil: realidade e perspectivas. In:

CANDAU, V.; SACAVINO, S. Educar em Direitos Humanos: construir democracia. Rio de Janeiro: DP\&A, 2000.

CANDAU, V. Educação, direitos humanos, currículo e estratégias pedagógicas, 2007. Disponível em: http://bit.ly/1EbrbL8. Acesso em: 15 dez.14.

Direito à educação, diversidade e educação em direitos humanos. Educação e Sociedade, Campinas, v. 33, n. 120, p. 715-726, 2012.

CÂNDIDO, A. O direito à literatura. In: Vários escritos. [versão eletrônica]. São Paulo: Duas Cidades, 2004.

CARVALHO, J. S. Educação, cidadania e Direitos Humanos. Rio de Janeiro: Vozes, 2004.

CARVALHO J.S; SESTI, A. P.; ANDRADE, J. P.; SANTOS, L. S.; TIBÉRIO, W. Formação de professores e educação em direitos humanos e cidadania: dos conceitos às ações. Educação e Pesquisa. São Paulo, v.30, n.3, p. 435-445, set./dez. 2004.

Educação e direitos humanos: um balanço sobre formação de professores. $\overline{\mathrm{ORG}}$ \& DEMO, Marília, v.11, n.1, p. 121-132, jan./jun., 2010.

DALLARI, D. de A. Um breve histórico dos direitos humanos. In: CARVALHO, José Sérgio de (Org.). Educação, cidadania e direitos humanos. Petrópolis, RJ: Vozes, 2004.

FERNANDES, Y. S.; CANDAU, V. M. F. Direito à qualidade da educação e educação em direitos humanos. Educação. Porto Alegre, v. 40, n. 1, p. 2-9, jan.-abr. 2017.

FREIRE, P. Pedagogia da esperança. Um reencontro com a Pedagogia do oprimido. Rio de Janeiro: Paz e Terra, 2006.

Pedagogia do Oprimido. $10^{\mathrm{a}}$ ed. Rio de Janeiro: Paz e Terra,1974.

LINDGREN ALVES, J. A. A declaração dos direitos humanos na pósmodernidade. A agenda social da ONU contra a desrazão 'pós-moderna'. Revista Brasileira de Ciências Sociais, n.30, ano 11, São Paulo, ANPOCS, fevereiro de 1996. 
MAGALHÃES, S. M. O. Educação para a paz, educação em direitos humanos, formação docente: entre aplausos e ceticismos, 2011.

<http://educaparaapaz.blogspot.com.br/p/i-seminario-de-educacao-da-paz-anais.html> MAIA, L. M. Educação em direitos humanos e tratados internacionais de direitos humanos. In: SILVEIRA, R. M. G. et. al. (Orgs.). Educação em direitos humanos: fundamentos teórico-metodológicos. João Pessoa: Editora Universitária, 2007.

PADILHA, P. R. Educação Em Direitos Humanos sob a Ótica dos Ensinamentos de Paulo Freire, Revista Múltiplas Leituras, v.1, n. 2, p. 23-35, jul. / dez. 2008.

PIOVESAN, F.; FACHIN, M. G. Educação em Direitos Humanos no Brasil. Revista Jurídica da Presidência. Brasília, v. 19 n. 117, Fev./Maio 2017.

SAVIANI, D. Vicissitudes e perspectivas do direito à educação no Brasil: abordagem histórica e situação atual. Educação e Sociedade, Campinas, v. 34, n. 124, p. 743-760, 2013.

SILVA, V. L. de S. Educar para a conexão: uma visão transdisciplinar de educação para saúde integral. Blumenau: Nova Letra, 2004 